\title{
CENTRO DE ARTE CONTEMPORÁNEO DE GALICIA EN SANTIAGO DE COMPOSTELA (GALICIA, ESPAÑA)
}

\author{
(CENTRE OF CONTEMPORARY ART OF GALICIA SANTIAGO DE \\ COMPOSTELA. GALICIA, SPAIN)
}

Álvaro Siza Vieira, Arquitecto

Fecha de recepción: 24-VIII-95

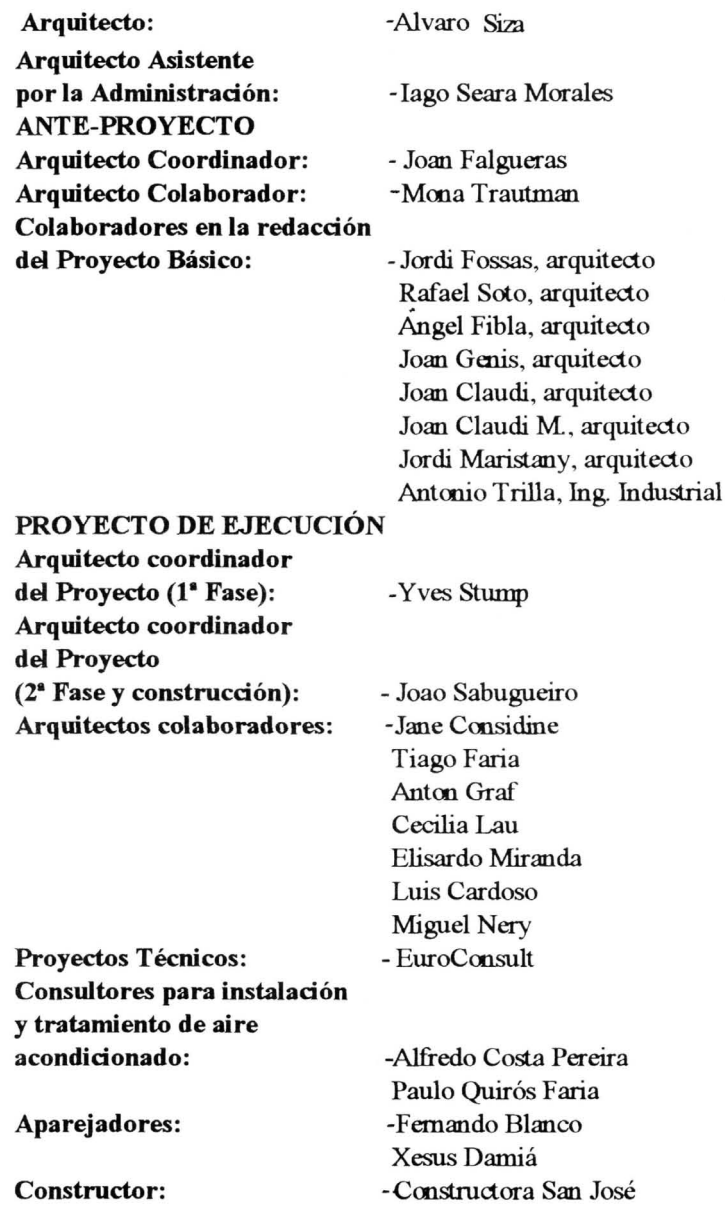

\section{RESUMEN}

Se describe -de manera breve-el desarrollo del proyecto del edificio Centro Gallego de Arte Contemporáneo. Las diferentes intervenciones en la zona donde queda asentado terminarán por unificar los espacios colindantes. El arquitecto reinterpreta el orden urbanistico preexistente en el entorno. La intervención se complementa con la rehabilitación de la huerta y cementerio de San Domingos de Bonaval, hoy recuperados como zona verde para la ciudad.

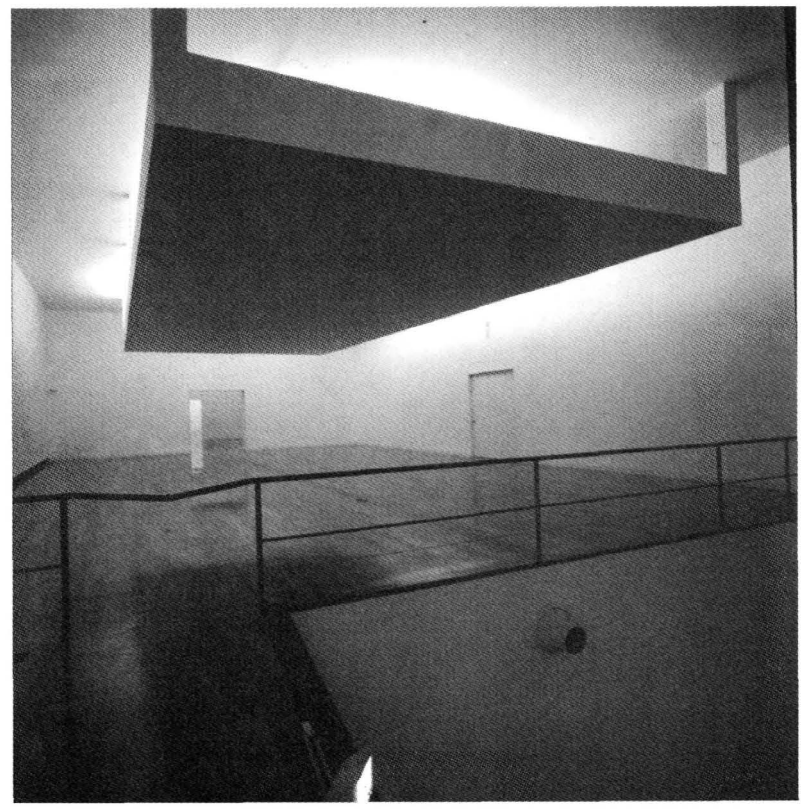

\section{SUMMARY}

The paper briefly describes the development of the design for the Galician Centre of Contemporary Art. The various actions to be perfomed in the area where the Centre is located will eventually give rise to the unity of the adjacent areas. The architect has re-interpreted the previously existing architectural order of the surroundings. The action will be complemented by the rehabilitation of the orchard and cemetery of San Domingos de Bonaval, now recuperated as a green area for the city.

un área que engloba el convento de San Roque, el convento de San Domingos, la porta do Camiño, el bloque comprendido entre la rúa das Rodas y la de Valle-Inclán y los espacios libres y plataformas adyacentes. 


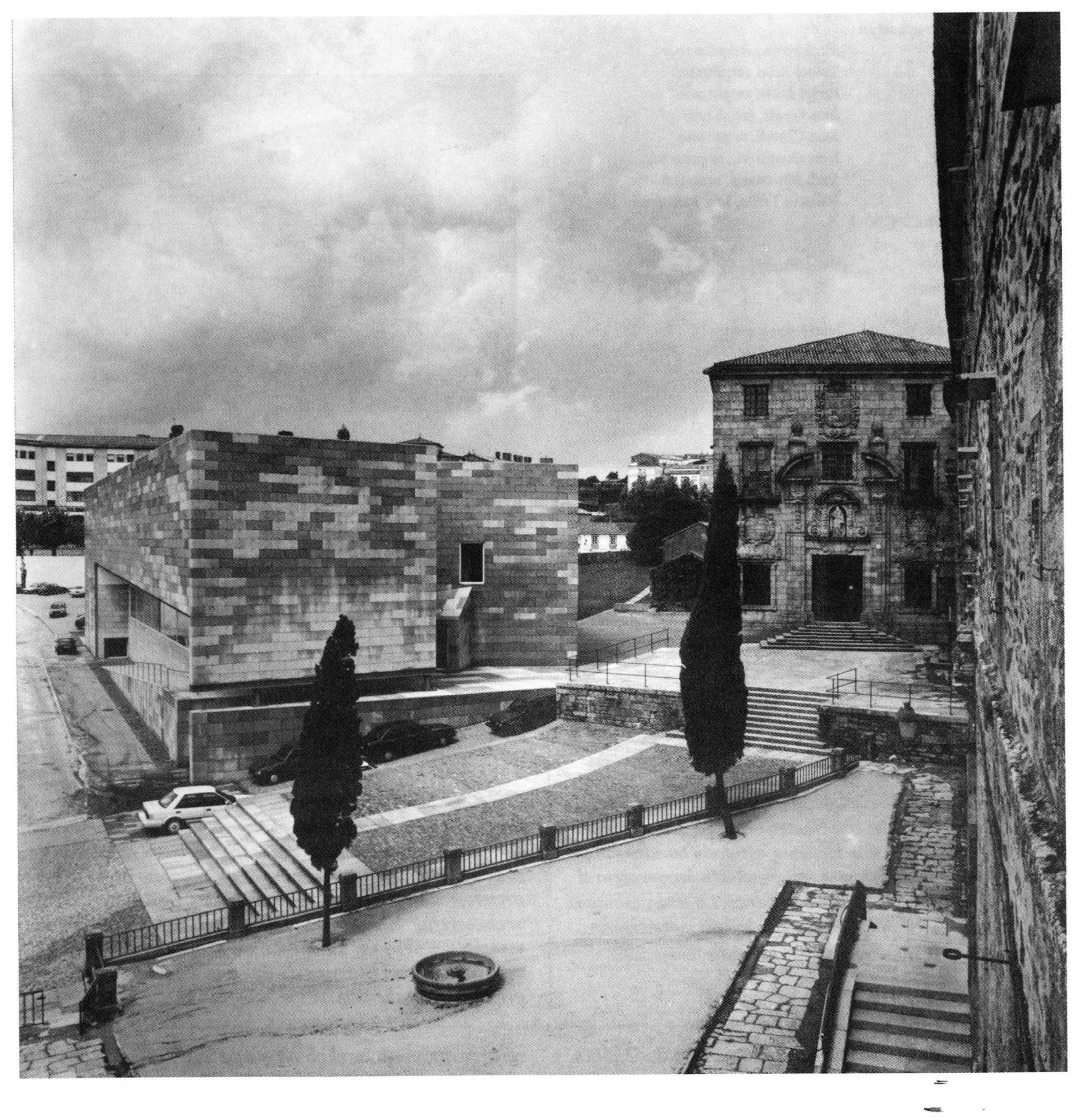




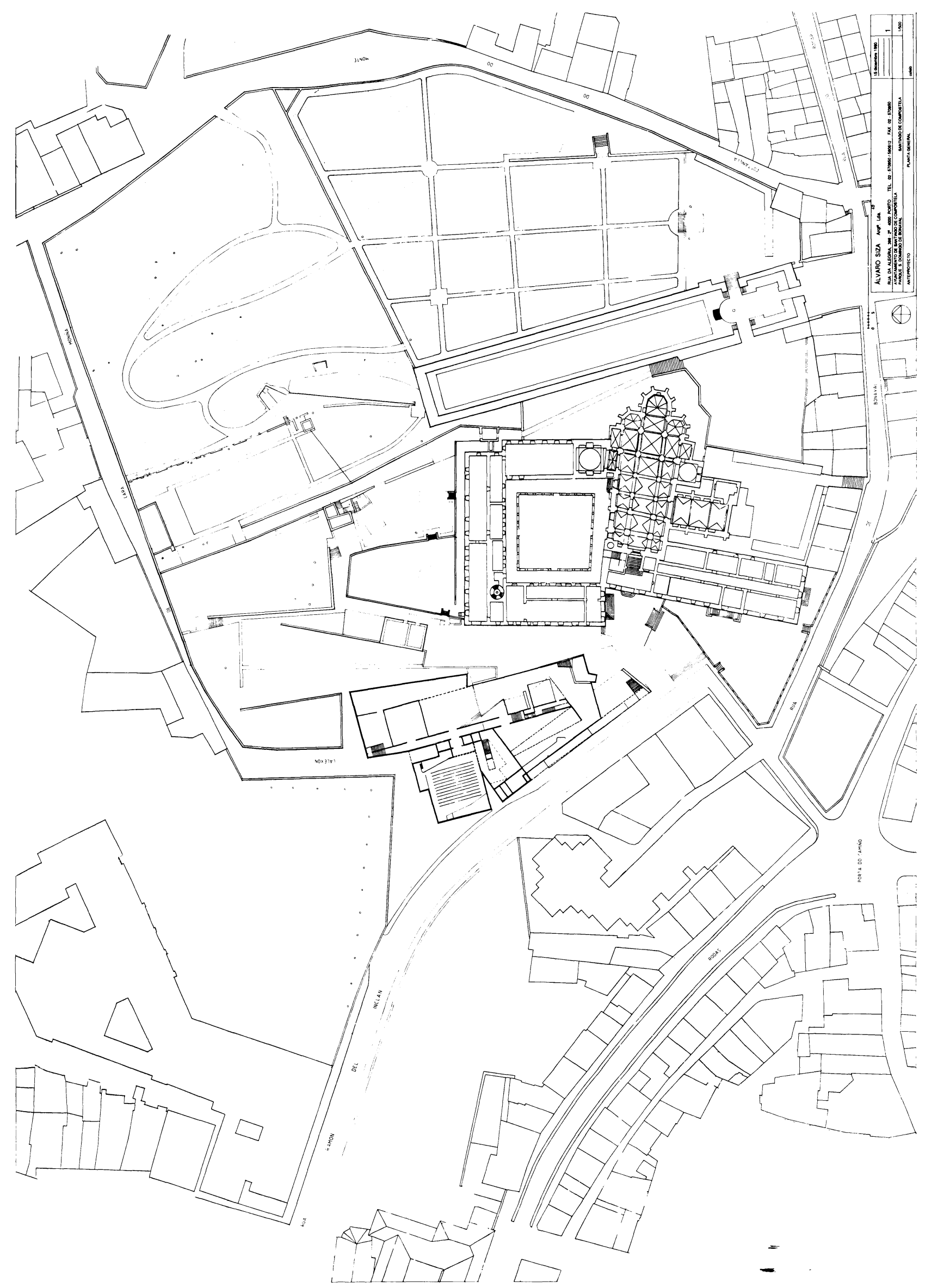


La localización propuesta aproxima la entrada principal del Centro de Arte Contemporáneo de Galicia a las entradas del convento y de la iglesia de San Domingos, resultando una estructura con un desarrollo sensiblemente longitudinal en la dirección Sur-Norte, limitada por dos frentes: al Oeste (paralela a la rúa de Valle-Inclán)y al Este (paralelaal cementerio de Bonaval), respectivamente. Este último frente establece un ángulo de $21^{\circ}$ con la fachada oeste y de $16^{\circ}$ con la fachada frontal del convento de San Domingos. Los frentes Norte y Sur, que completan la defínición del área construida, están condicionados al Norte por la esquina del muro de soporte del recinto del colegio La Salle y por la rúa da Caramoniñay al Sur por los portales de acceso al convento y a la iglesia de San Domingos.

Esta opción presenta difíciles problemas, sobre todo en lo que se refiere a la proximidad de los portales mencionados,

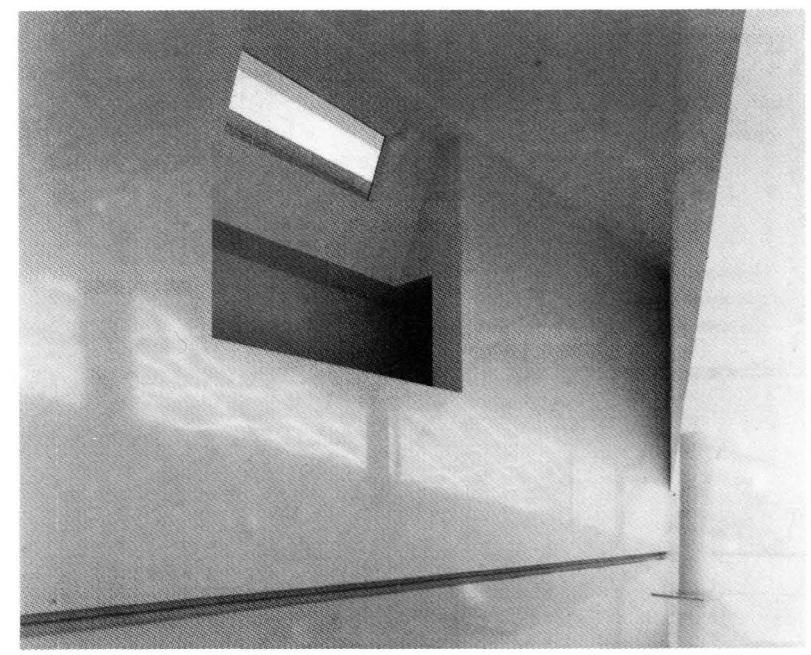

de gran expresión arquitectónica, no siendo tenida en cuenta sin antes considerar la posible alternativa: retirada del Centro de Arte Contemporáneo de Galicia hacia el terreno al Norte del recinto del convento, liberando completamente su frente Oeste. La idea de esta última hipótesis se basa en los siguientes motivos:

a) La importancia cívica del nuevo edificio apunta cara a la franca participación en los espacios públicos adyacentes (la rúa de Valle-Inclán y la sucesión de plataformas entre la porta do Camiño y San Domingos), sin lo cual tendería a la condición de un simple anexoy a una renuncia relativa a la expresión de su contenido.

b) La implantación propuesta permite intervenir decisivamente en la ordenación de una zona actualmente confusa y en cierto modo degradada, definiendo un espacio unificador de sucesivas intervenciones, nunca determinadas por un estudio de conjunto (particularmente en lo que se refiere a la apertura de la rúa de Valle-Inclán y al colegio La Salle y respectivo muro de soporte). Permite, además, integrar la recuperación del jardín al Este del convento de San Roque y de las plataformas de acceso al convento de San Domingos.

c) El frente Oeste del convento de San Domingos no estaba originariamente expuesto; su aparición en el paisaje urbano estaba condicionada por los muros del recinto, estando el acceso a los portales encuadrado por estos muros y por el propio edificio.

La solución propuesta traduce, por tanto, el propósito de rehacer un orden preexistente y destruido, utilizando la fuerza transformadora que justamente compete a un Centro de Arte Contemporáneo de Galicia.

Las razones y objetivos anteriormente descritos obligan a un cuidadoso estudio de volúmenes, materiales y lenguaje.

La gran dificultad en el desarrollo del proyecto se refiere a su inserción en un espacio que, poco a poco, se ha ido llenando de edificios de muy diferente escala y significación, relacionados sólo en parte y de forma relativa. Compete al Centro de Arte Contemporáneo de Galicia mediar en estas difíciles relaciones, transformando un aglomerado de edificios y espacios en un tejido coherente, englobando tanto el convento de San Domingos como cualquier modesta construcción, lo mismo una plaza que un jardín privado.

Los volúmenes considerados y ya descritos, en lo que se refiere a su implantación, se definen también por una altura común, correspondiendo aproximadamente al remate de las portadas del convento y de la iglesia de San Domingos. Esto es, la relación del Centro de Arte Contemporáneo de Galicia con el convento mantiene la preponderanciade éste en el contexto urbano, sustituyéndose, en cierto modo y en este sentido, el muro de límite del correspondiente recinto, hasta entonces derrumbado. Simultáneamente, el volumen adoptado se constituye como mediador entre las escaleras del convento, del bloque entre las rúas de Valle-Inclán y das Rodas y del colegio La Salle, rematando con el aislamiento entre estas diferentes realizaciones y multiplicando las relaciones de alineamiento y otras.

Los criterios de preservación-transformación defendidos incluyen particularmente la elección de materiales de revestimiento. Se optó por un aplacado de granito en las superficies exteriores del edificio, variando ocasionalmente el color de este material, de modo que permita una clara lectura de los cuerpos que lo constituyen. A esta elección no fueron ajenas las características del clima de Santiago, además de la persistencia de los materiales tradicionales.

Debe subrayarse que el uso del granito asume una expresión propia del sistema constructivo al que se subordina, el cual se refiere a una estructura de cemento caracterizada por el uso de grandes vanos abiertos. - 
Consecuentemente con las opciones descritas, el edificio se caracteriza por la existencia de dos cuerpos de tres pisos y terraza accesible, ambos con planta en forma de L (A al Oeste y B al Este), que convergen según la dirección NorteSur; estos dos cuerpos determinan un espacio intermedio de forma triangular (C) que ocupa la altura total.

El programa pedido se distribuye por estos sectores A, B y $\mathrm{C}$, de la siguiente manera:

Cuerpo A: Engloba, fundamentalmente de Sur a Norte y en planta baja, el pórtico de acceso, las zonas de distribución y recepción (incluyendo los mostradores de control y de vestuario), y además, ocupando el ala de menor desarrollo de la L, el vestíbulo de acceso a la Sala de Actos y al primer piso. En la primera planta, este cuerpo incluye el vestíbulo de acceso a la biblioteca y al centro de documentación y a la zona administrativa.

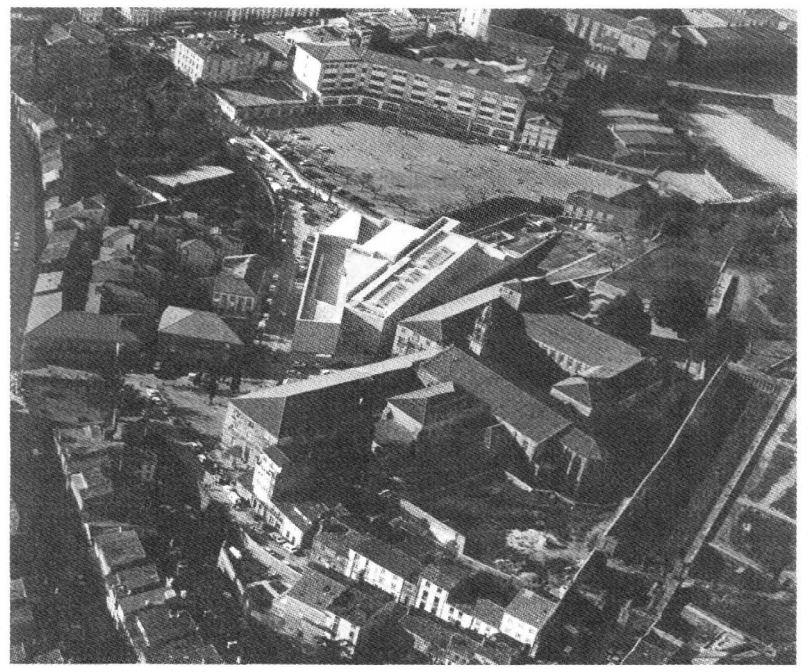

Cuerpo B: Engloba, en el sótano, las áreas de exposiciones situadas en la mitad Norte del brazo de mayor desarrollo. Engloba también, de Sur a Norte y en planta baja, las zonas de acceso público no condicionado (librería, cafetería) y las áreas de exposiciones temporales, así como la sala de actos con sus divisiones de apoyo, que ocupan la sala de menor desarrollo de la L. En el primer piso, y sobre esta altura, se sitúa el centro de documentación, mientras que el área de exposición permanente se extiende a lo largo del ala de mayor desarrollo.

El espacio triangular entre los cuerpos A y B constituye una zona de transición iluminada desde arriba, en la que se sitúa la puerta de control de acceso a las salas de exposición temporal y permanente.

El patio de acceso principal conecta los dos cuerpos A y B en el extremo Sur del edificio e incluye un acceso y una zona abierta sobre la zona pública del sótano (instalaciones sanitarias, zona de descanso y cabinas telefónicas).
Zonas de servicios internos del piso 3 - $1^{\text {er }}$ nivel: incluyen los servicios administrativos -a lo largo del cuerpo A- y la oficina de dirección en el extremo Sur del cuerpo A. Estos servicios disponen de un acceso privado por escaleras, controlando el patio principal de la planta baja, además del acceso público por escaleras y ascensor. Disponen también de trabazón interna privada con las áreas de servicio del sótano y de exposiciones permanentes.

Zonas públicas de la terraza: las áreas de la terraza sobre el cuerpo $\mathrm{A}$, accesibles al público, pudiéndose realizar en ellas exposiciones de escultura. Los muros de límite de esta terraza tienen una altura de $3,20 \mathrm{~m}$, elevándose la cota del piso en el extremo Sur del edificio, de modo que permi- ta la existencia de un mirador sobre la ciudad, accesible por una amplia rampa

Zonas de servicios internos de la terraza: están constituidas por los depósitos del centro de documentación, situados

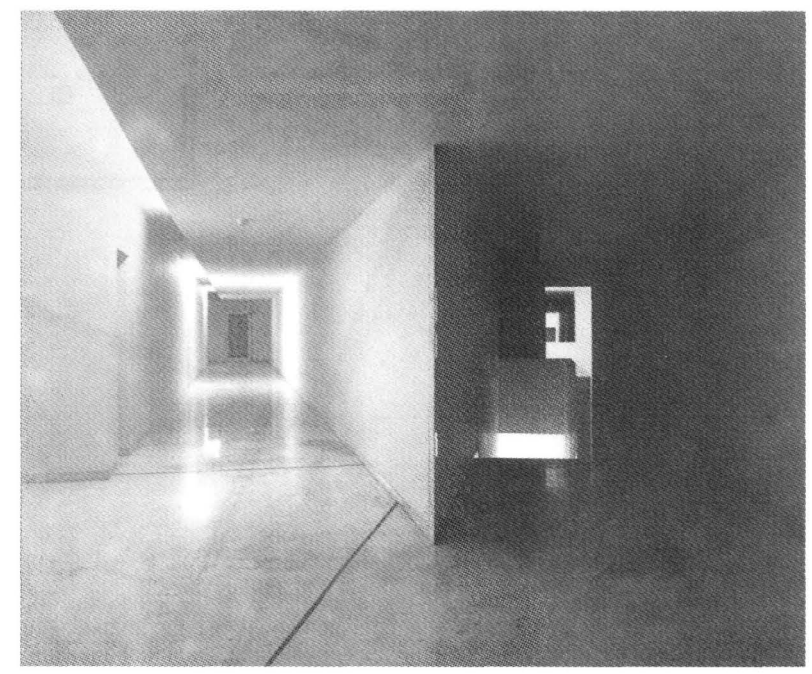

sobre el desarrollo del mismo en el primer piso y por las zonas de cubierta de los cuerpos B y C, apenas accesibles para la limpieza de los lucernarios.

El sótano del edificio ocupa la totalidad del área correspondiente a los cuerpos A, B y C. En el área correspondiente a los cuerpos A y C se sitúan los servicios de apoyo a las salas de exposición (montaje de exposiciones y mantenimiento, depósito, talleres de restauración y almacenes de la cafetería y de la librería). El cuerpo B, además de las áreas de exposición ya mencionadas y de la zona correspondiente al brazo de menor desarrollo, engloba un área en el extremo Sur, correspondiente a la zona pública de aseos y vestíbulo ya mencionada, así como una sala de depósito. El brazo de mayor desarrollo del cuerpo $B$ incluye también una franja de tres metros de ancho, que corresponde a una galería de servicio que interrelaciona las principales comunicaciones verticales (escaleras, ascensores y montacargas). Éstas abarcan la totalidad de los pisos y la terraza. 

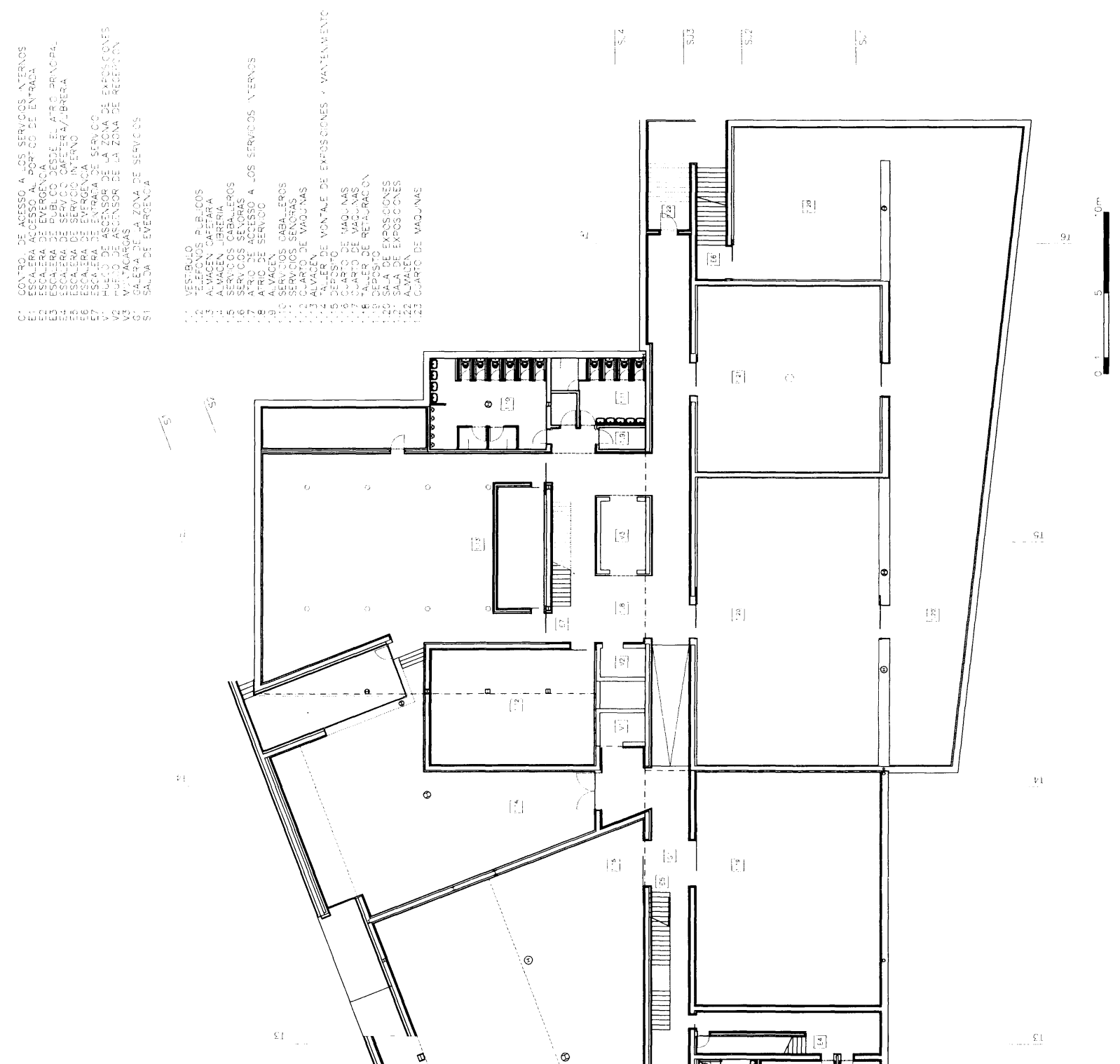

筫

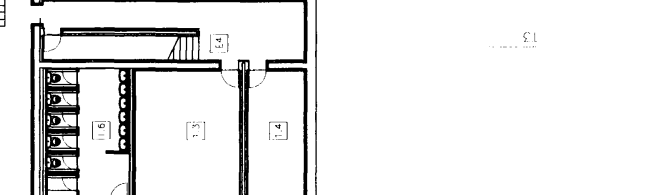



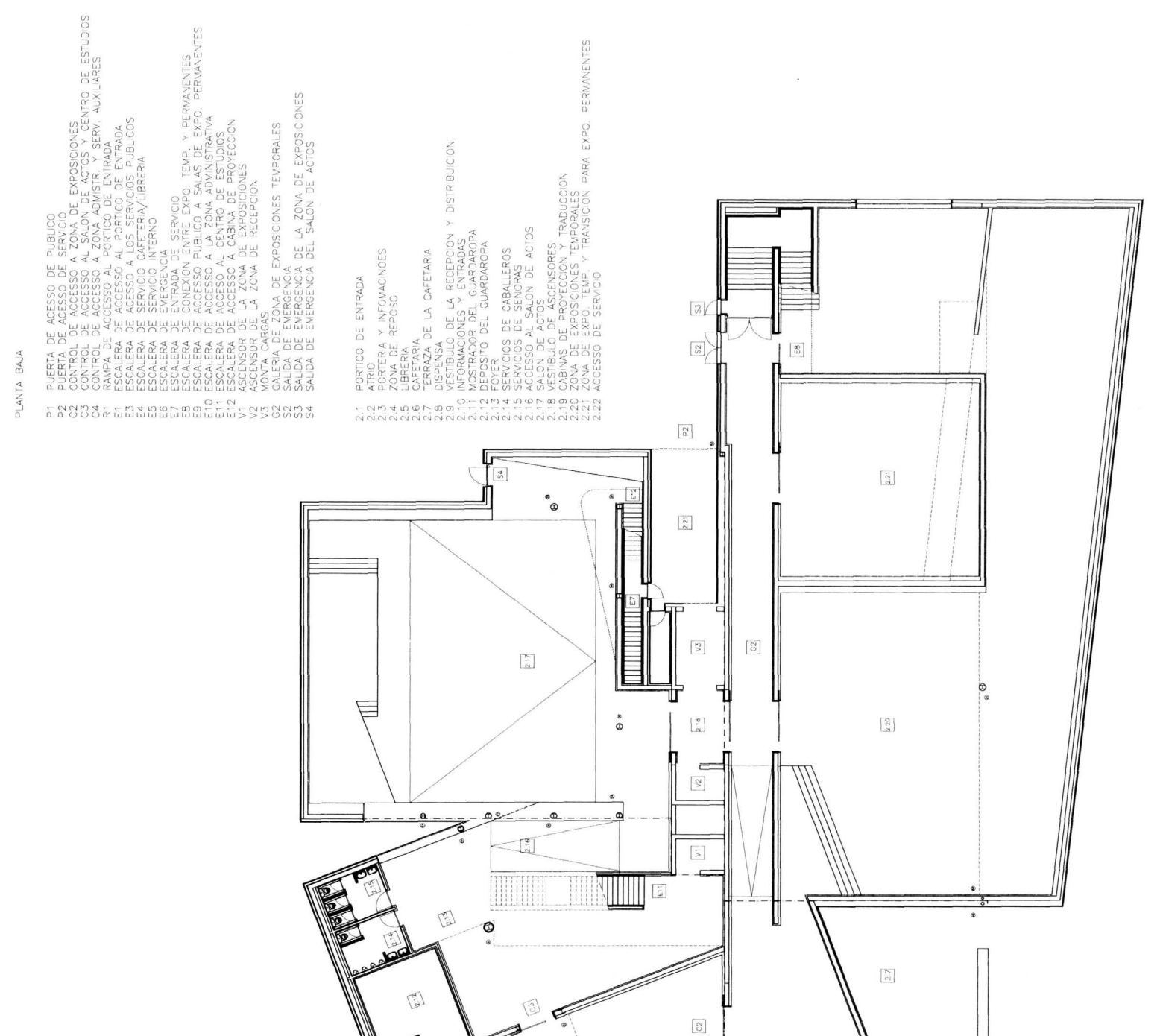


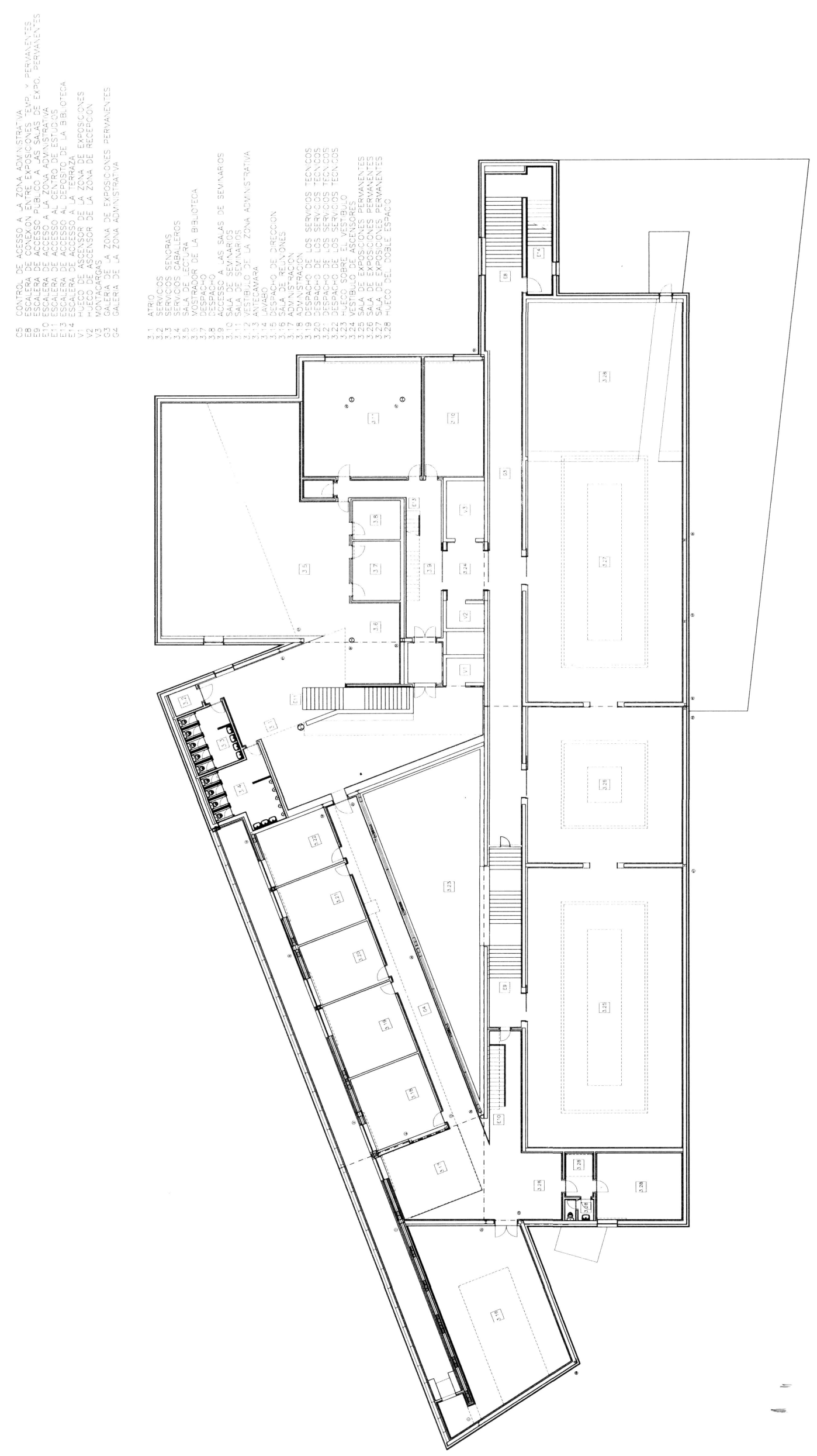



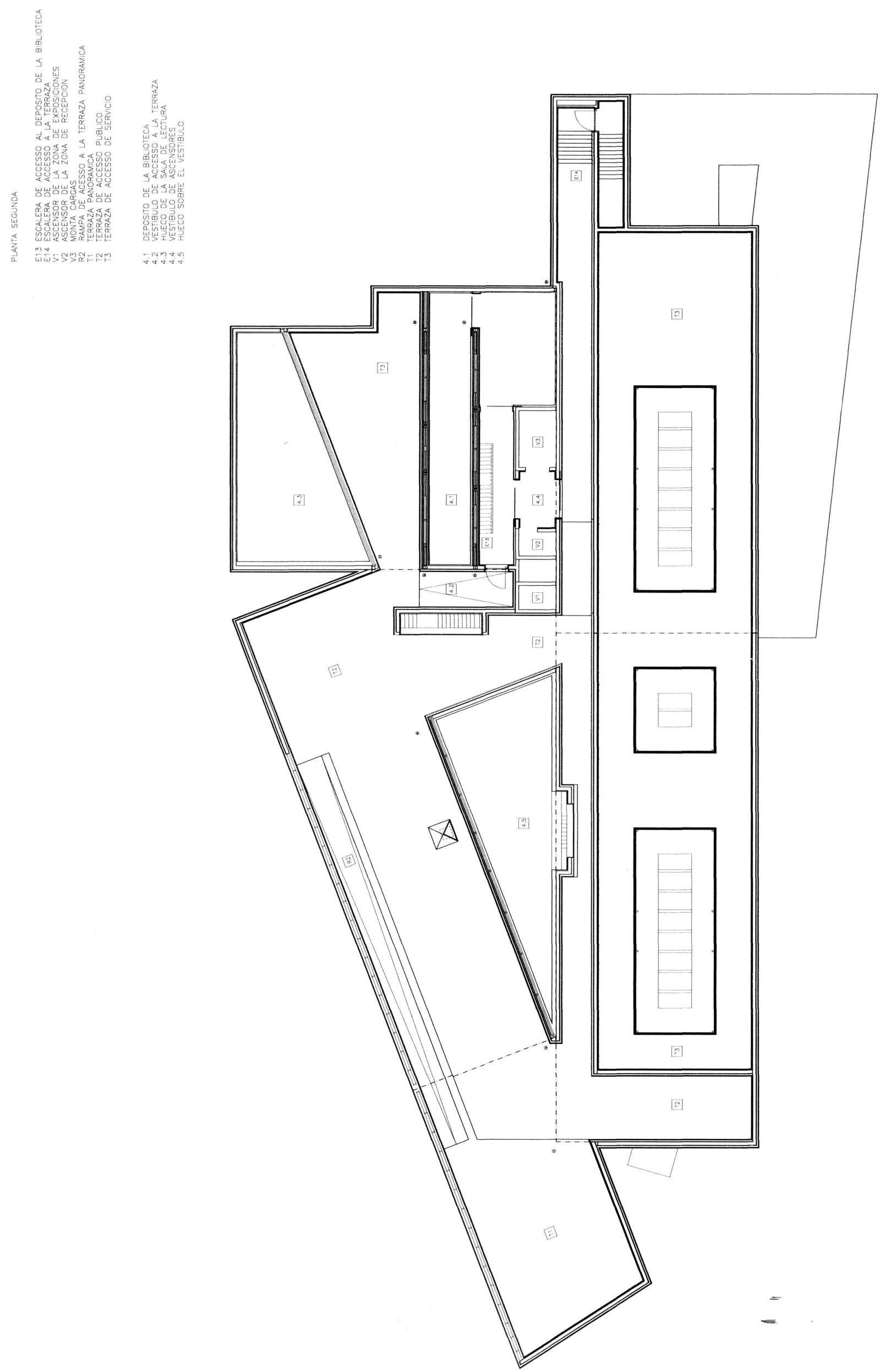

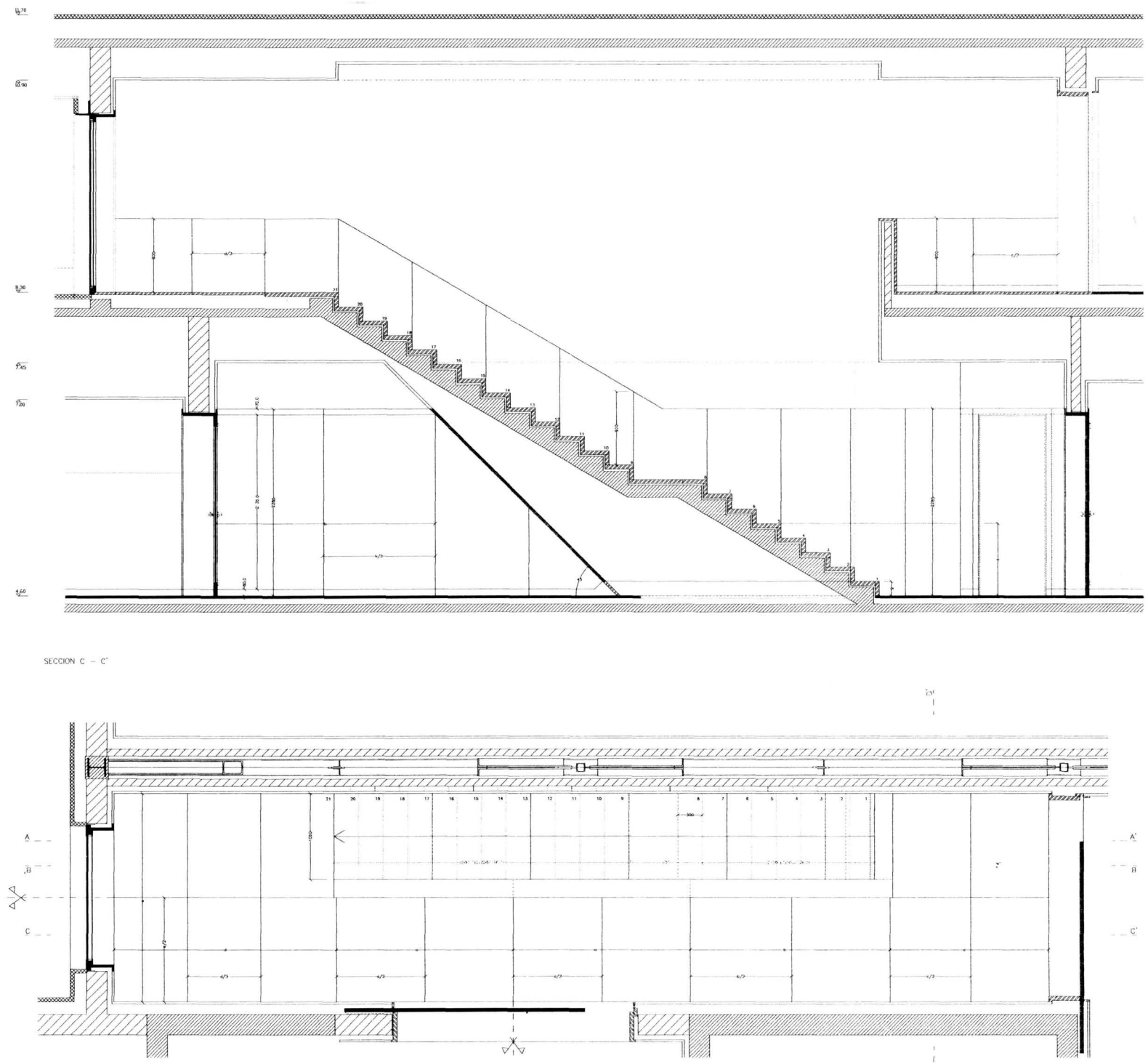

SECCION HORIONIA

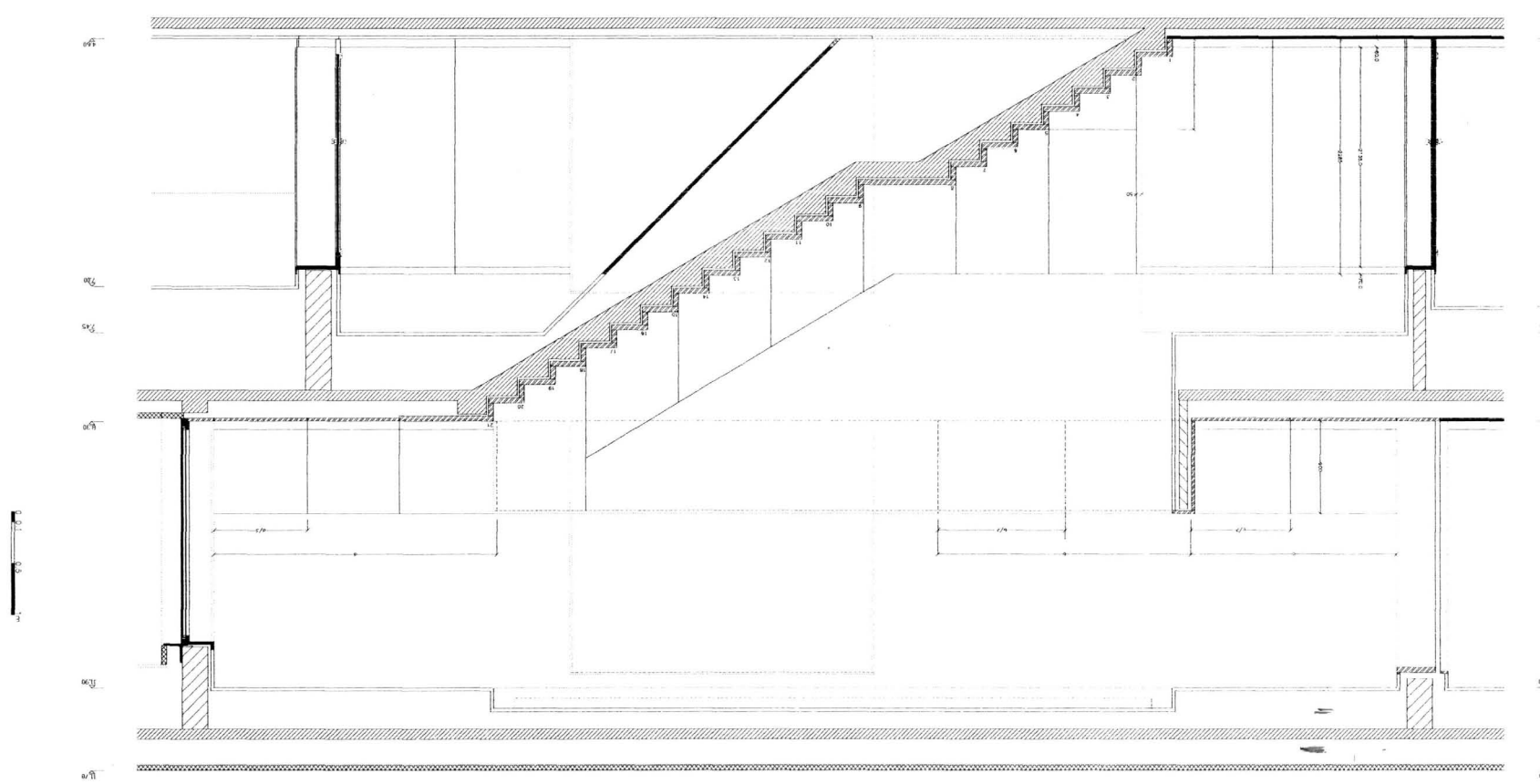



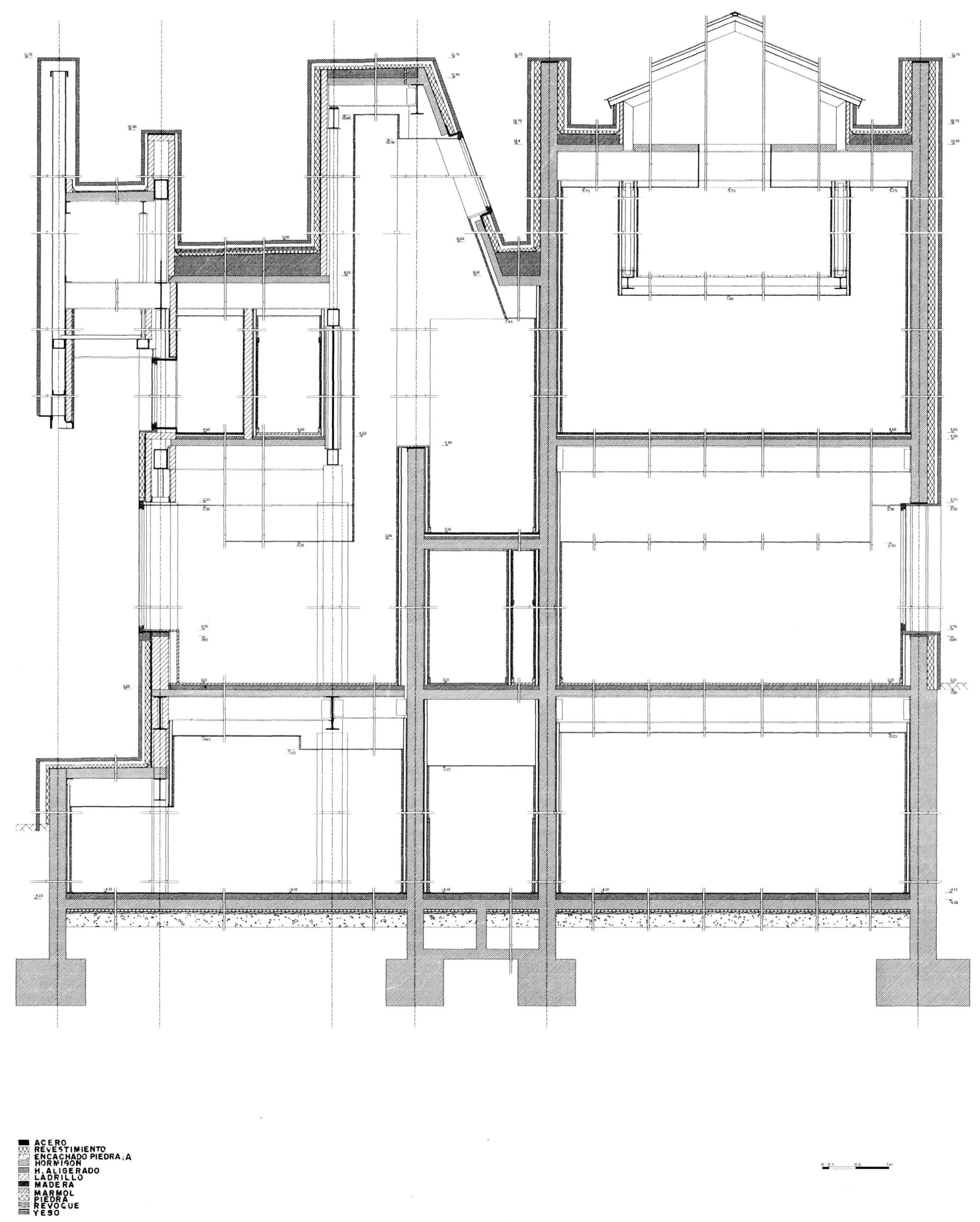

Sección transversal. 


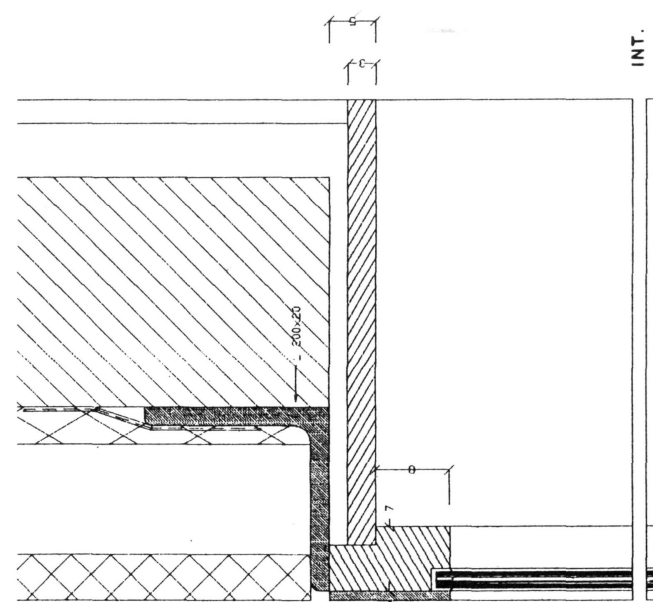

完
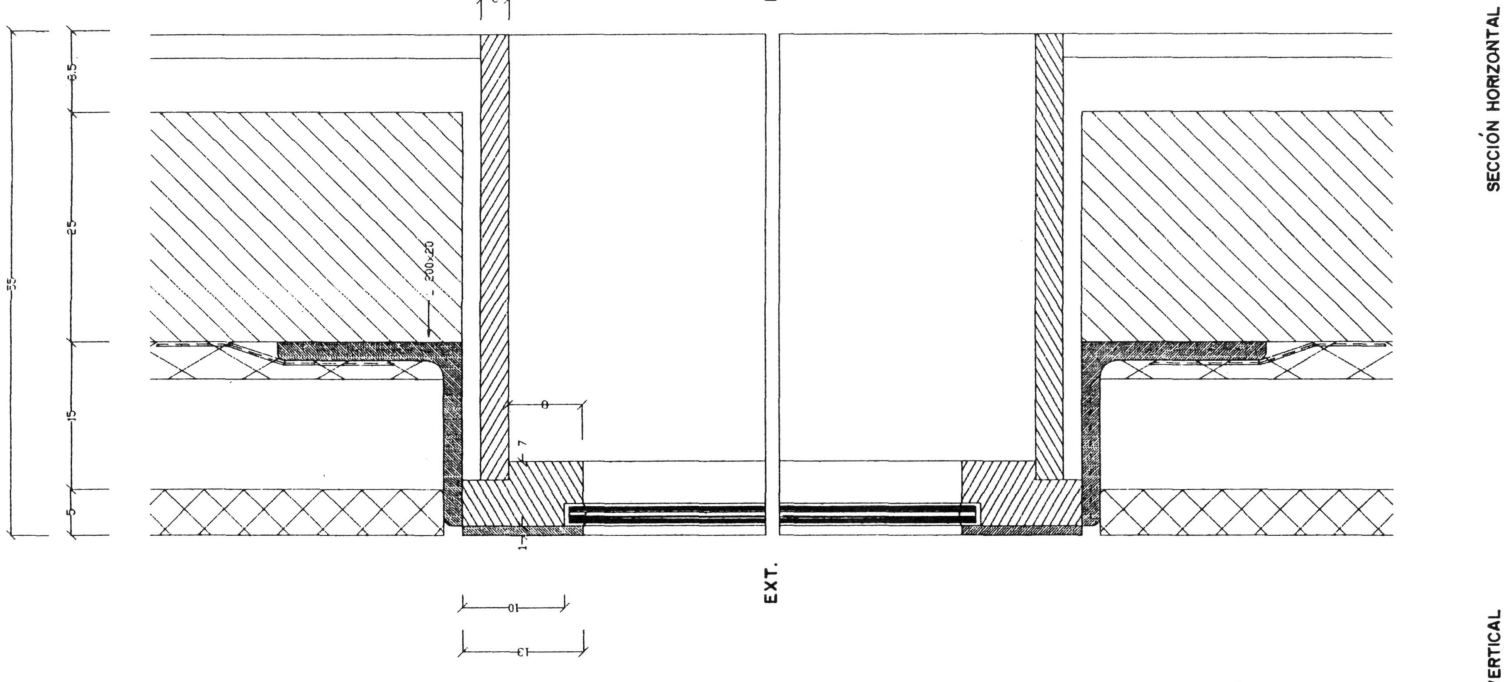

悹
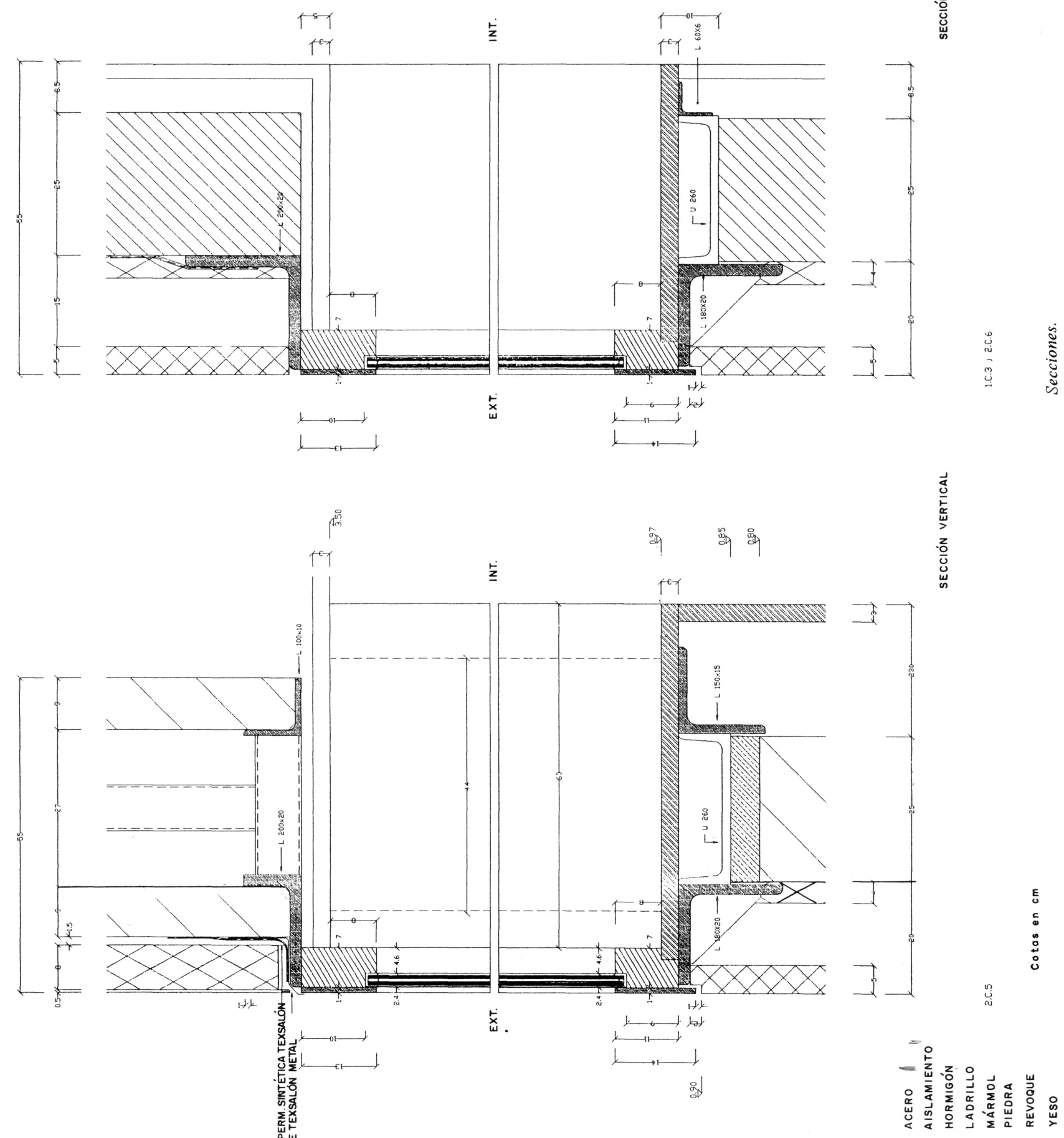

(c) Consejo Superior de Investigacion

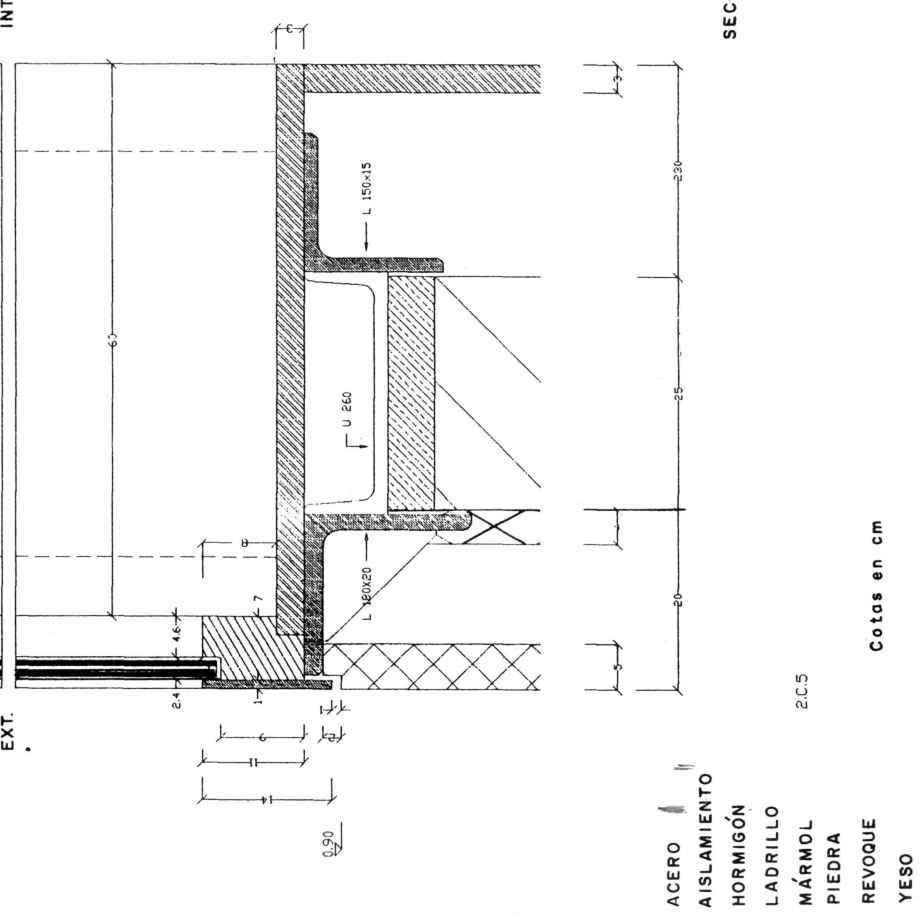



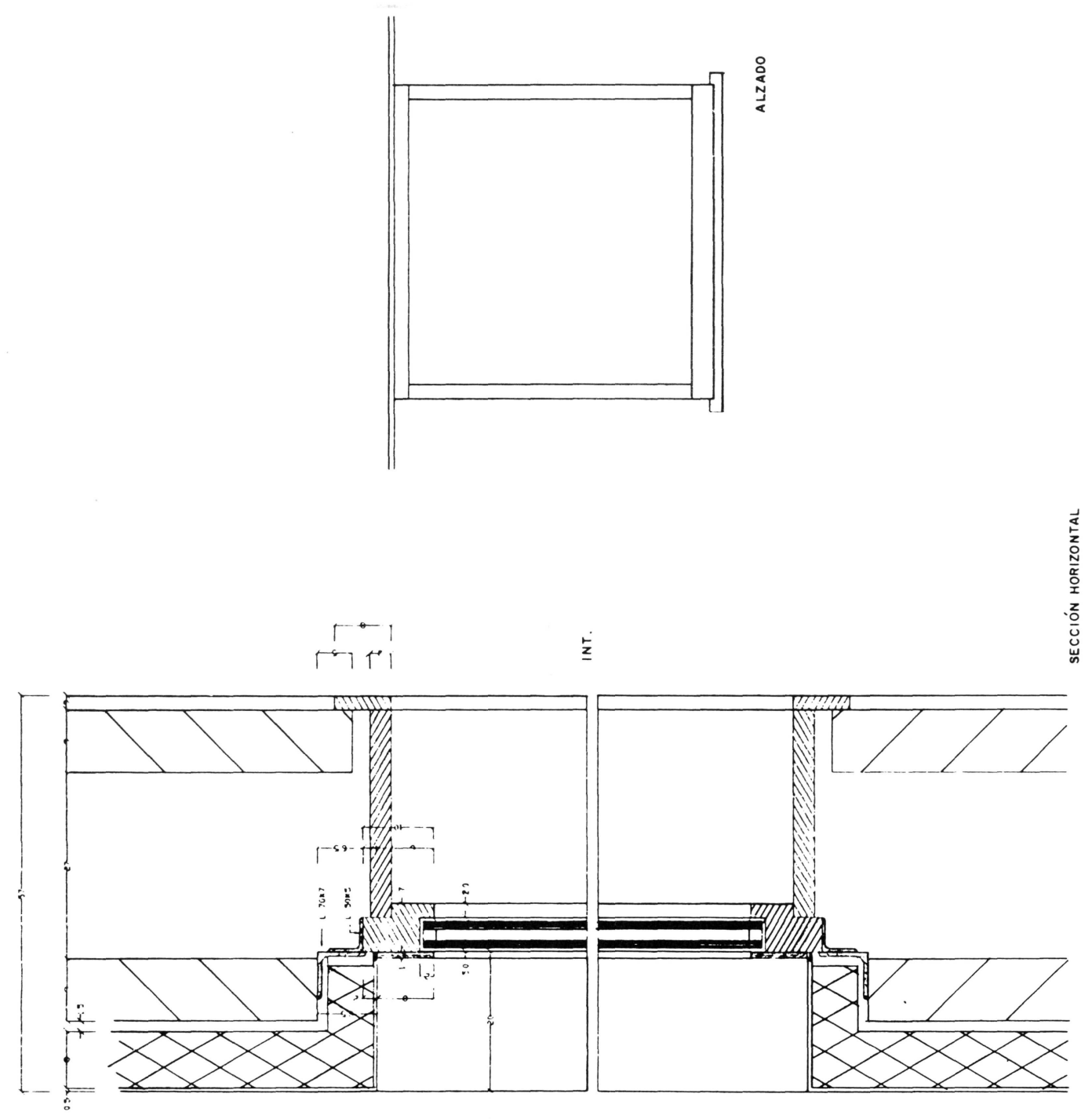

岳

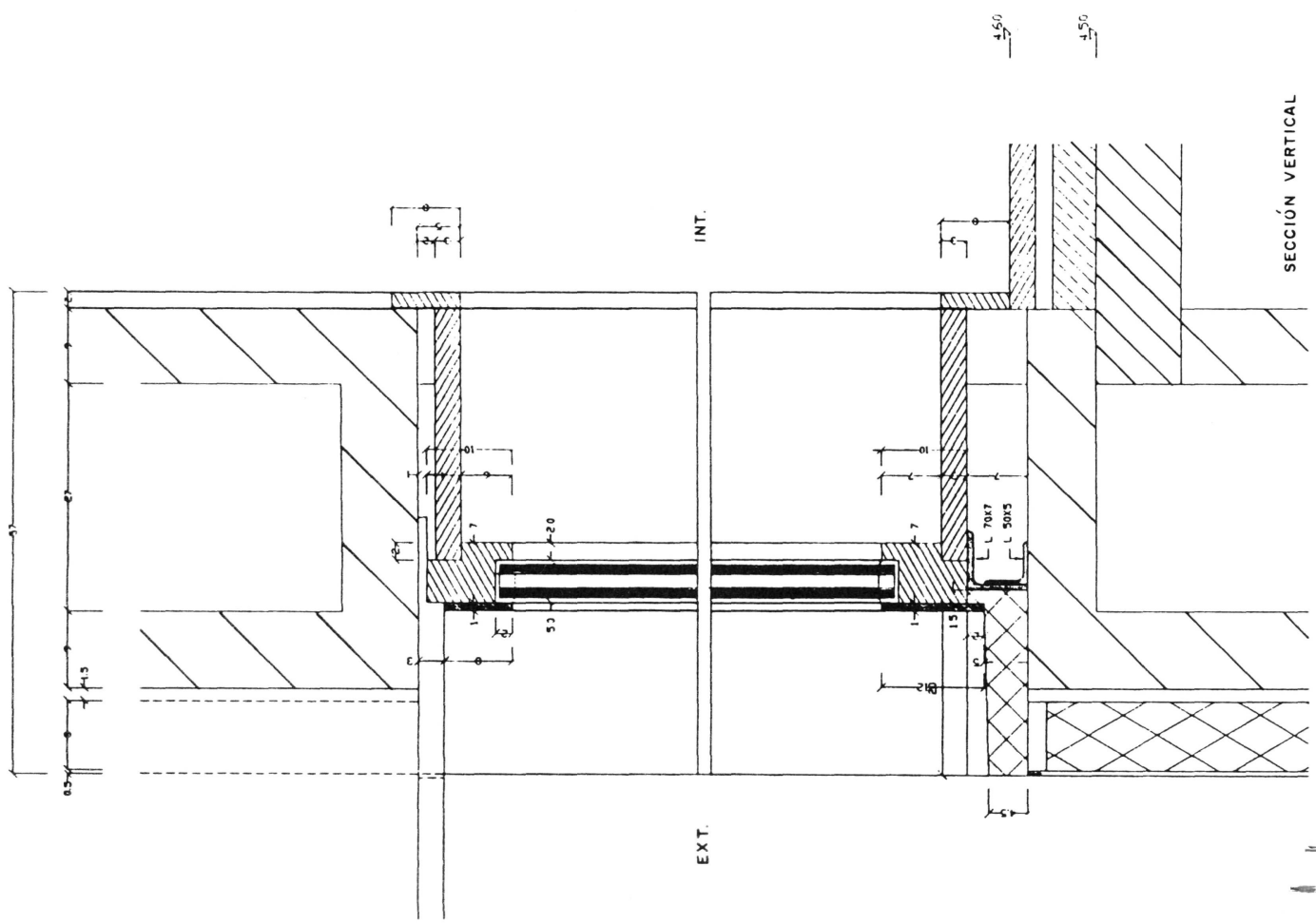



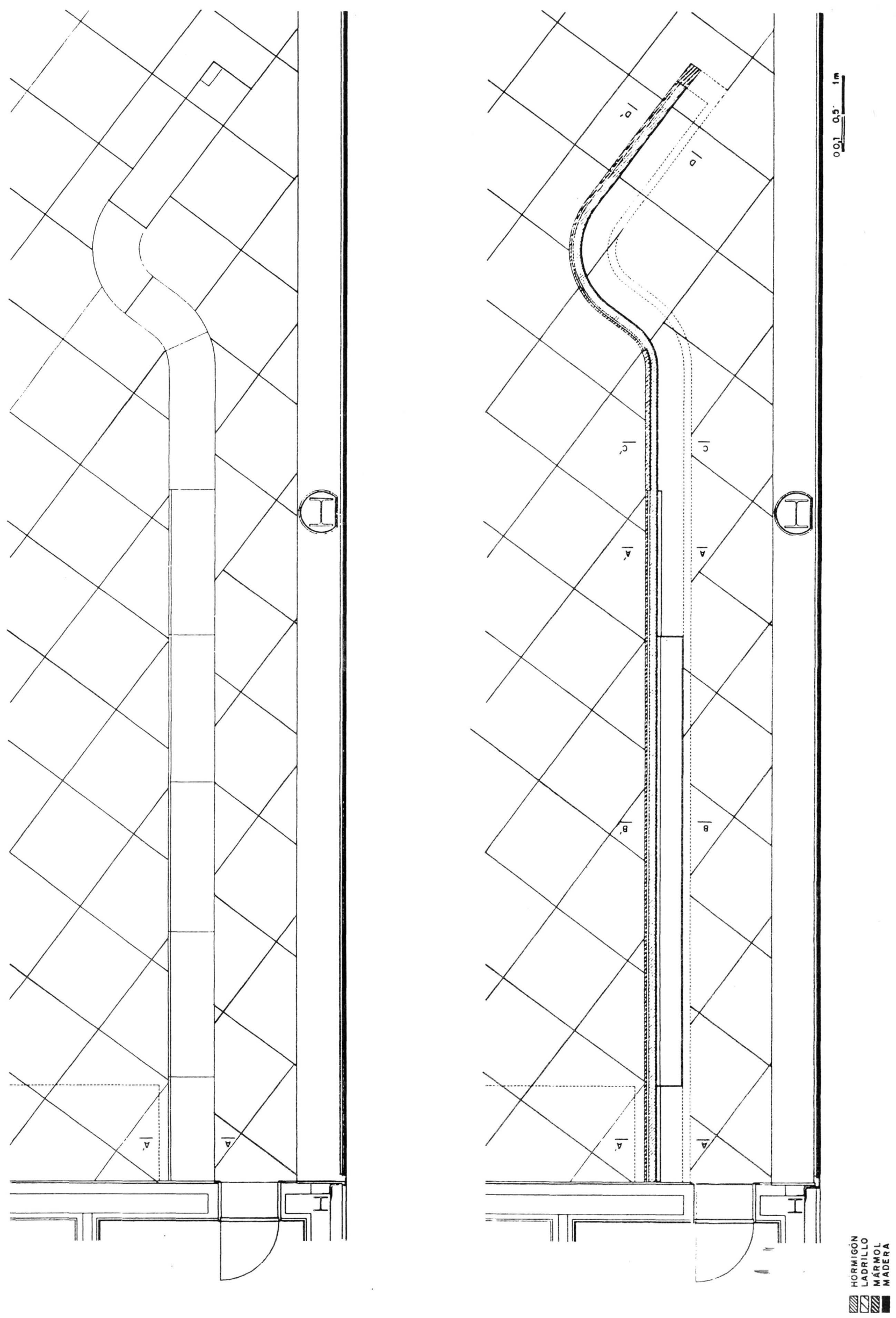


$$
\begin{aligned}
& F_{1} \sqrt{f_{1}} \\
& f_{1}
\end{aligned}
$$



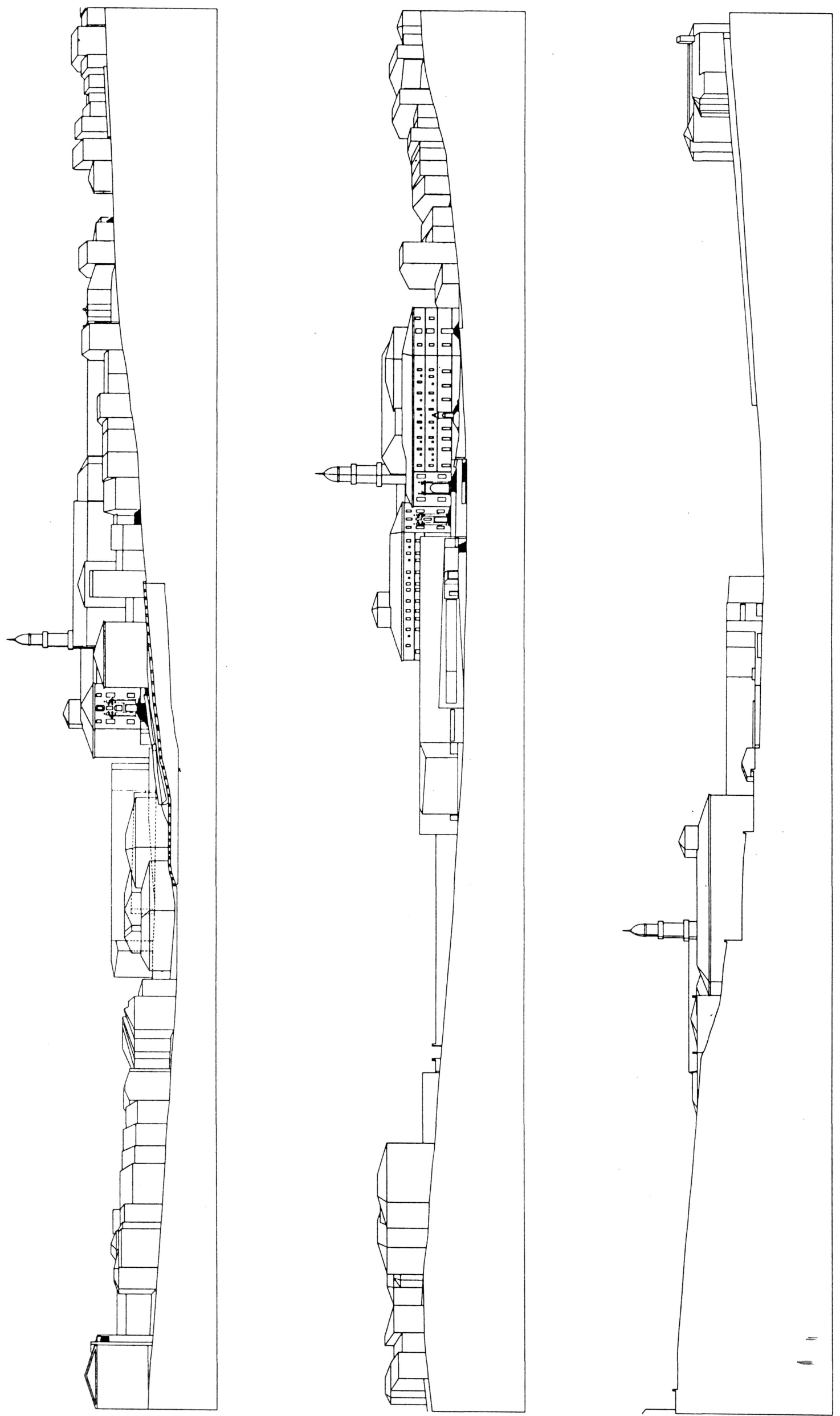

(c) Consejo Superior de Investigaciones Científicas Licencia Creative Commons 3.0 España (by-nc) 


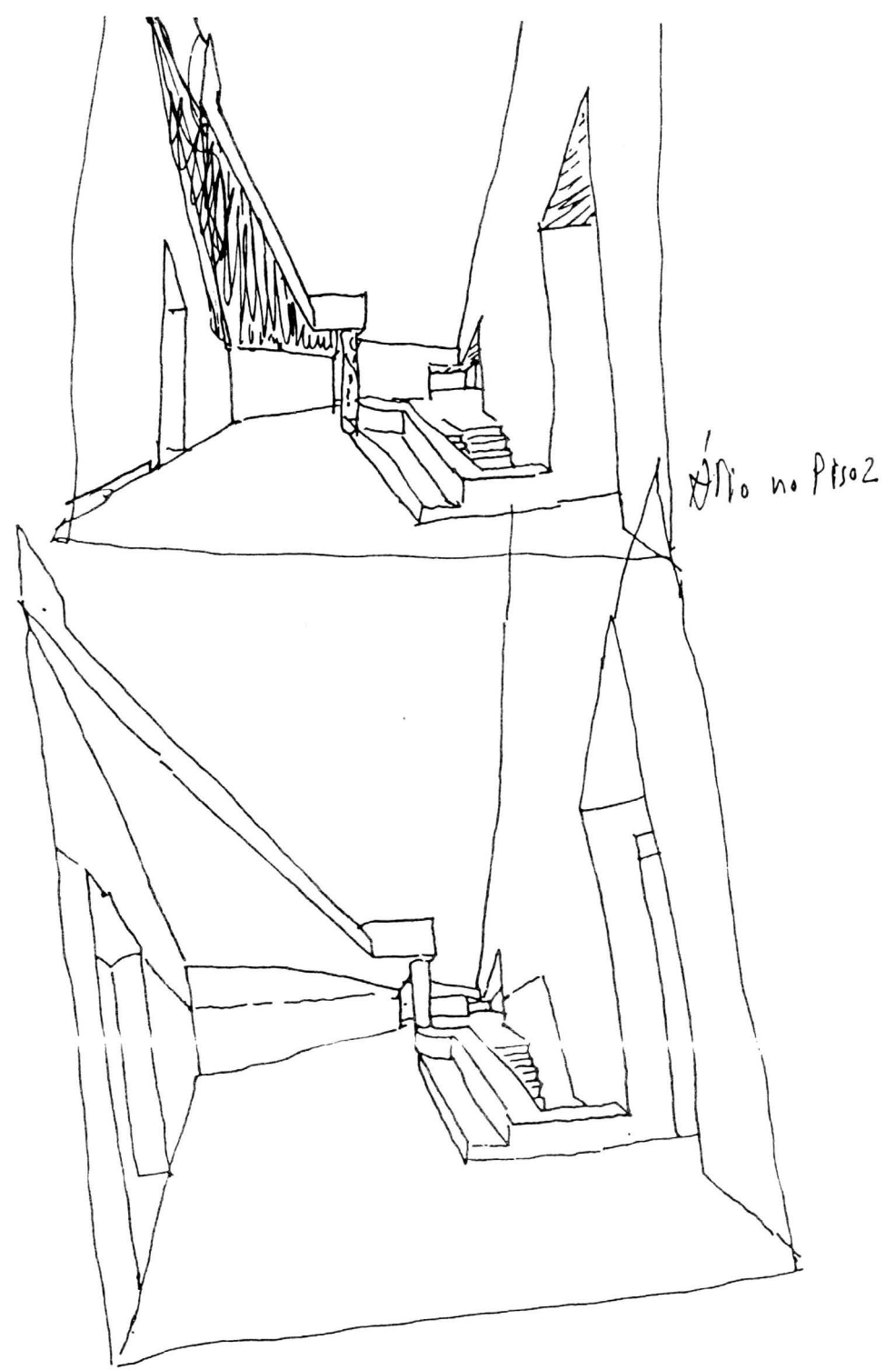

